\title{
Molecular cloning and characterization of $\mathrm{Ca}^{2+}$-dependent inducible nitric oxide synthase from guinea-pig lung
}

\author{
Manabu SHIRATO, Tohru SAKAMOT0, Yoshiyuki UCHIDA', Akihiro NOMURA, Yukio ISHII, Hiroaki IIJIMA, Yukio GOT0 \\ and Shizuo HASEGAWA \\ Department of Pulmonary Medicine, Institute of Clinical Medicine, University of Tsukuba, 1-1-1 Tennoudai Tsukuba, Ibaraki 305-8575, Japan
}

\begin{abstract}
We have isolated a full-length cDNA for an inducible nitric oxide synthase (iNOS) from guinea-pig lung. The cDNA has a $3447 \mathrm{bp}$ open reading frame encoding 1149 amino acid residues. The deduced amino acid sequence is approx. $80 \%$ identical with iNOS of human epithelial cells and murine macrophages. Consensus recognition sites for cofactors are highly conserved. COS cell lysate transfected with the guinea-pig iNOS shows significant levels of nitric oxide synthase (NOS) activity, and this is inhibited by $79 \%$ by chelation of $\mathrm{Ca}^{2+}$ ions. The NOS activity is restored in a concentration-dependent manner by increasing the free $\mathrm{Ca}^{2+}$
\end{abstract}

level. The NOS activity is also inhibited by trifluoperazine, a calmodulin antagonist, which suggests that the $\mathrm{Ca}^{2+}$ dependence is due to $\mathrm{Ca}^{2+}$-dependent calmodulin binding to the enzyme. Northern blot analysis reveals that the cloned iNOS mRNA is expressed in the lung and the colon in normal guinea pigs. Stimulation in vivo by lipopolysaccharide induces the expression of iNOS in the kidney, the spleen and the colon, but in the lung the same stimulation decreases its expression. These results suggest that the cloned guinea-pig iNOS is distinct in characteristics and expression from previously described iNOS forms.

\section{INTRODUCTION}

Nitric oxide (NO) is produced from L-arginine by a catalytic action of NO synthase (NOS) in various tissues and has been recognized as a regulator of a variety of physiological and pathophysiological functions. Three distinct isoforms of NOS have been described [1,2]. Constitutively expressed endothelial NOS (eNOS) and neuronal NOS (nNOS) are regulated by the agonist-stimulated elevation of the intracellular $\mathrm{Ca}^{2+}$ level and produce small amounts of NO, which is involved in homeostatic processes such as blood pressure regulation and neurotransmission. In contrast it has been reported that inducible $\mathrm{Ca}^{2+}$ independent NOS (iNOS) is barely detectable in resting cells but is up-regulated by stimulation with lipopolysaccharide (LPS) and/or proinflammatory cytokines. The iNOS binds calmodulin tightly and is not dependent on $\mathrm{Ca}^{2+}$ elevation above basal physiological intracellular levels [3]. The iNOS isoform produces large amounts of NO that can act beneficially as a host defence system but also causes tissue damage in certain inflammatory diseases.

Recent studies, however, have demonstrated that some iNOSs are $\mathrm{Ca}^{2+}$-dependent for their activity [4,5], and also constitutively expressed [6,7]. In contrast the $\mathrm{Ca}^{2+}$-dependent NOS can be induced by exposure to endotoxins [8]. Therefore inducible and $\mathrm{Ca}^{2+}$-independent NOS activity is not always a good indication of iNOS. In the present study we have isolated a guinea-pig lung iNOS that is $\mathrm{Ca}^{2+}$-dependent as well as constitutively expressed and whose mRNA expression in the lung is inhibited by stimulation with LPS.

\section{MATERIALS AND METHODS}

PCR-based cloning of iNOS from guinea-pig lung

Total RNA was extracted from Hartley guinea-pig lung with a RNeasy total RNA kit (Qiagen, Hilden, Germany). To determine
5 - and 3 '-end sequences of the guinea-pig iNOS, rapid amplification of cDNA ends (RACE) was performed with a Marathon cDNA amplification kit (Clontech, Palo Alto, CA, U.S.A.). The gene specific primers were 5'-AGGTTGGACCACTGTATCCT$3^{\prime}$ for 5'-RACE and 5'-AGATGAGAGTGGCAGCTACTGGGT-3' for 3'-RACE. In addition, we obtained a 739 bp DNA fragment of the middle portion of the guinea-pig iNOS by reverse transcriptase-mediated PCR (RT-PCR) with another set of gene-specific primers, 5'-CAGCGCTACAACATCCTGGA$3^{\prime}$ and 5'-GAGGGTACATGCTGGAGCC-3'. The sequences of all these primers were highly conserved between iNOS sequences of murine macrophages (GenBank accession number M84373) [9], rat liver (GenBank accession number D12520) [10] and human hepatocytes (GenBank accession number L09210) [5]. Each of the PCR products was subcloned into a cloning vector, pCR II (Invitrogen, San Diego, CA, U.S.A.) and sequenced by the dideoxynucleotide chain-termination method with a dideoxyterminator kit (Perkin Elmer, Foster City, CA, U.S.A.) and a DNA sequencer model 373S (Perkin Elmer Applied Biosystems Division). On the basis of the sequences obtained, two sets of primers were synthesized to cover the open reading frame: fragment 1 forward, 5'-ATGGCCTGCCCCTGGAATTTCCTGTGGAAG- ${ }^{\prime}$; fragment 1 reverse, 5'-CAGCTGGTACTGATCCATGCAGAGAACCTT-3' ; fragment 2 forward, 5'-GATGCGCAAGATGATGGCCTCCCGAGTCAG-3'; fragment 2 reverse, 5'-ACTCTGAAAGTCTCTAGGGGTCCTCAGAGC3'. RT-PCR was performed with a GeneAmp XL RNA PCR kit (Perkin Elmer) to make two overlapping iNOS cDNA species. The PCR products were subcloned into pCR II and sequenced. These two cDNA fragments were ligated at a $B \ln I$ site located in the overlapping region to make the full-length iNOS cDNA.

\section{Transient expression in COS-7 cells and assay of NOS activity}

The full-length guinea-pig iNOS cDNA and human chondrocyte

Abbreviations used: 1400W, N-[3-(aminomethyl)benzyl]acetamidine; eNOS, endothelial NOS; iNOS, inducible NOS; LPS, lipopolysaccharide; nNOS, neuronal NOS; NOS, nitric oxide synthase; RACE, rapid amplification of cDNA ends; RT-PCR, reverse transcriptase-mediated PCR.

1 To whom correspondence should be addressed (e-mail yuchida@md.tsukuba.ac.jp).

The nucleotide sequence data reported will appear in DDBJ, EMBL and GenBank Nucleotide Sequence Databases under the accession number AF027180. 


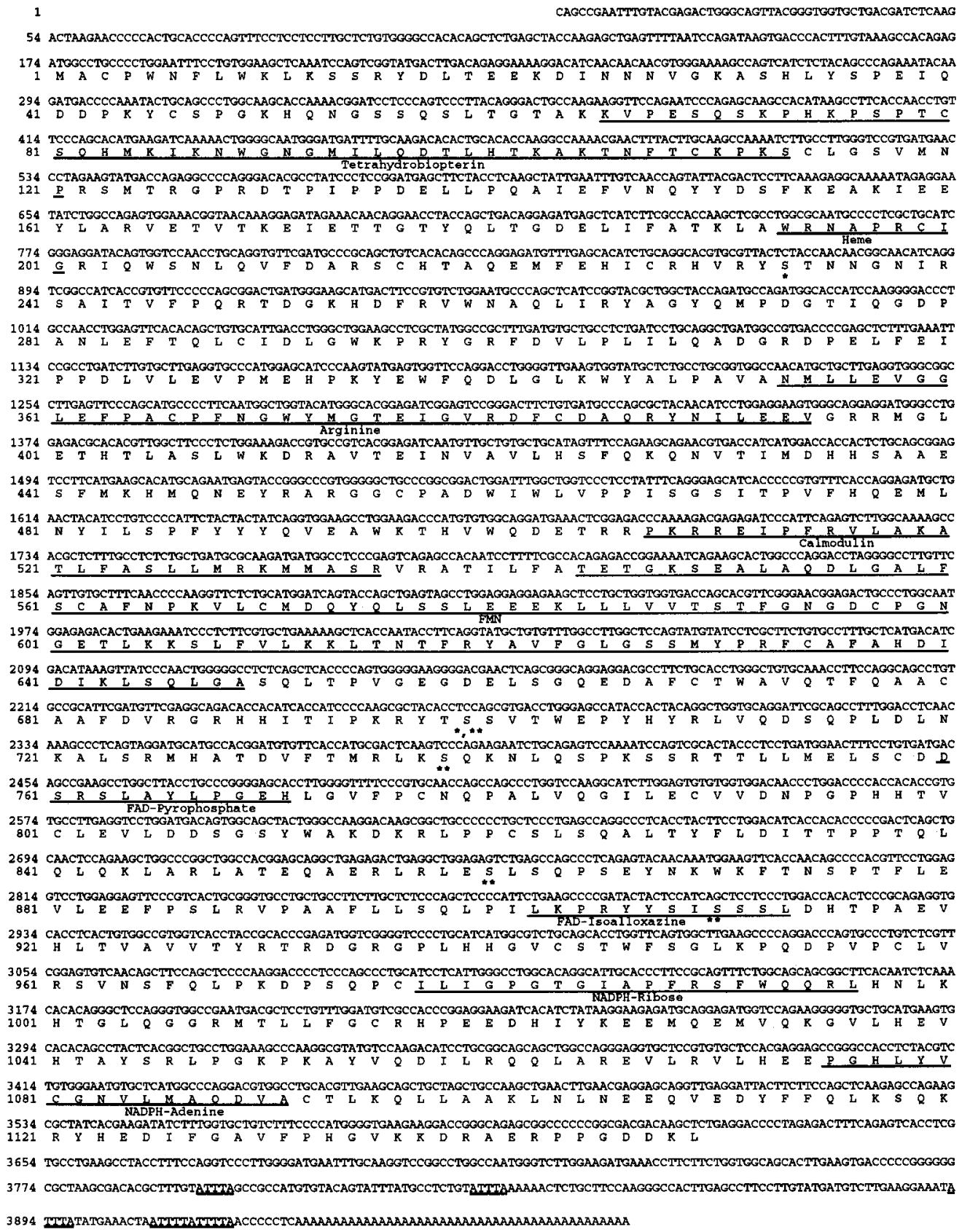

\section{Figure 1 Nucleotide and deduced amino acid sequences of guinea-pig iNOS}

The amino acid sequence is shown with the single-letter code. Consensus sequences of cofactor-recognition regions for tetrahydrobiopterin, haem, arginine, calmodulin, FMN, FAD and NADPH are underlined and labelled accordingly. Five $\mathrm{A}(\mathrm{T})_{n} \mathrm{~A}$ motifs in the last two lines are also underlined. Asterisks indicate a potential point of serine phosphorylation by protein kinase $\mathrm{A}$ (one asterisk) or calmodulin-dependent protein kinase (two asterisks).

iNOS cDNA (kindly provided by Dr. R. G. Knowles of GlaxoWellcome) [11] were inserted into pcDNAI expression vector (Invitrogen), which has a cytomegalovirus promoter. COS-7 cells were transfected with the complex of DNA and LipofectAmine (Gibco BRL, Rockville, MD, U.S.A.) in accordance with the manufacturer's instructions; $48 \mathrm{~h}$ after the transfection, the cells were harvested and lysed by freeze-thawing in $50 \mathrm{mM}$ Tris $/ \mathrm{HCl}$ buffer, $\mathrm{pH}$ 7.5, containing $1 \mathrm{mM}$ EDTA, $10 \mu \mathrm{M}$ leupeptin, $10 \mu \mathrm{M}$ pepstatin, $10 \mu \mathrm{M}$ bestatin and $1 \mathrm{mM}$ PMSF. After centrifugation at $1000 \mathrm{~g}$ for $10 \mathrm{~min}$, the supernatant was adjusted to a protein concentration of $20 \mu \mathrm{g} / \mu \mathrm{l}$ by the Bradford method [12]. The NOS activity of the supernatant was measured by the conversion of $\mathrm{L}-\left[2,3,4,5-{ }^{3} \mathrm{H}\right] \operatorname{arginine}(41.0 \mathrm{Ci} / \mathrm{mmol} ; 1 \mathrm{Ci}=37 \mathrm{Gbq})$ (Amersham, Little Chalfont, Bucks., U.K.) to L- $\left[2,3,4,5-{ }^{3} \mathrm{H}\right]$ citrulline with a nitric oxide synthase assay kit (Calbiochem, San Diego, CA, U.S.A.). The reaction buffer contained, in a final volume of $50 \mu 1,25 \mathrm{mM}$ Tris $/ \mathrm{HCl}, \mathrm{pH} 7.4,3 \mu \mathrm{M}$ tetrahydrobiopterin, $1 \mu \mathrm{M}$ FAD, $1 \mu \mathrm{M}$ FMN , $1 \mathrm{mM}$ NADPH, $0.1 \mu \mathrm{M}$ calmodulin, $1 \mathrm{mM}$ $\mathrm{CaCl}_{2}, 0.5 \mu \mathrm{M} \mathrm{L}-\left[2,3,4,5-{ }^{3} \mathrm{H}\right]$ arginine $(1 \mu \mathrm{Ci})$ and $1 \mu \mathrm{g} / \mu 1$ protein extract. Reactions proceeded for $15 \mathrm{~min}$ at room temperature 
and were quenched by the addition of $400 \mu \mathrm{l}$ of $50 \mathrm{mM}$ Hepes, pH 5.5, containing $5 \mathrm{mM}$ EDTA. After reaction, citrulline was separated from arginine with cation-exchange resin, and $\mathrm{L}-[2$, $\left.3,4,5-{ }^{3} \mathrm{H}\right]$ citrulline in the eluate was quantified by scintillation counting. To examine the effect of the $\mathrm{Ca}^{2+}$ level on NOS activity, $\mathrm{CaCl}_{2}$ in the reaction buffer was replaced with $1 \mathrm{mM} \mathrm{EGTA,} \mathrm{then}$ $\mathrm{CaCl}_{2}$ was added to the buffer at final concentrations of $10 \mu \mathrm{M}$ to $1 \mathrm{mM}$. Trifluoperazine, a calmodulin antagonist, was added to the buffer to investigate the effect of calmodulin binding on NOS activity. In some experiments, NOS inhibitors, $N$-[3-(aminomethyl)benzyl]acetamidine (1400W) [13] and L-thiocitrulline [14], were added to the reaction buffer.

\section{Northern blot analysis}

Guinea pigs were injected intravenously with $4 \mathrm{mg} / \mathrm{kg}$ of LPS (Sigma, St. Louis, MO, U.S.A.) in $0.9 \% \mathrm{NaCl}$ or vehicle $(0.9 \%$ $\mathrm{NaCl})$. The serotype of the LPS was Escherichia coli 055 :B5. At 6 hours after injection, total RNA was extracted from various tissues; $10 \mu \mathrm{g}$ of total RNA from each tissue was separated on a $4 \%$ formaldehyde $/ 1 \%$ agarose gel. After transfer to Hybond $\mathrm{N}+$ (Amersham), RNA was hybridized with $\left[{ }^{32} \mathrm{P}\right] \mathrm{dCTP}$-labelled cDNA probe at $68^{\circ} \mathrm{C}$ in ExpressHyb hybridization solution (Clontech), and washed at $50{ }^{\circ} \mathrm{C}$ in $0.1 \times \mathrm{SSC} / 0.1 \% \mathrm{SDS}$ (SSC is $0.15 \mathrm{M} \mathrm{NaCl} / 0.015 \mathrm{M}$ sodium citrate). The membrane was exposed to a BAS-SR imaging plate (Fuji Film, Tokyo, Japan), and analysed by an imaging analyser BAS5000 (Fuji Film).

\section{Data analysis}

Data were analysed for statistical significance by Bonferroni multiple comparison test. Values were considered statistically significant at $P<0.05$.

\section{RESULTS}

\section{Identification of a guinea-pig homologue of iNOS}

The complete nucleotide sequence and the deduced amino acid sequence are shown in Figure 1. To avoid nucleotide misincorporations into RT-PCR products, we used a high-fidelity DNA polymerase from Thermus thermophilus. The cDNA has a $3447 \mathrm{bp}$ open reading frame encoding a protein of 1149 residues with a calculated molecular mass of $131 \mathrm{kDa}$. The ATG start site (CAGAGATGG) is compatible with the consensus sequence for the translational initiation of eukaryotic mRNA species [15]. Two in-frame stop codons precede the start site by 45 and 60 bases. The cDNA has five $\mathrm{A}(\mathrm{T})_{n} \mathrm{~A}$ motifs in the $3^{\prime}$ untranslated region, which might be associated with the instability of the mRNA of inducible proteins such as proinflammatory cytokines and proto-oncogenes [16]. No polyadenylation signal (AATAAA) is identified in the cDNA sequence. The similarity of the amino acid sequence of iNOS to those from human airway epithelium [6] and murine macrophage cell lines [9] is $80 \%$ and $79 \%$ respectively. In contrast, the amino acid sequence is $37 \%$ identical to human neuronal NOS [17] and $24 \%$ identical to human endothelial NOS [18]. The binding domains for tetrahydrobiopterin, haem, arginine, calmodulin, FMN, FAD and NADPH are highly conserved. The deduced amino acid sequence lacks the autoinhibitory control element that is specific for eNOSs and nNOSs and prevents calmodulin binding and enzymic activation [19]. Putative phosphorylation motifs by protein kinase $\mathrm{A}$ and calmodulin-dependent protein kinase but not protein kinase $\mathrm{C}$ have been identified [20].

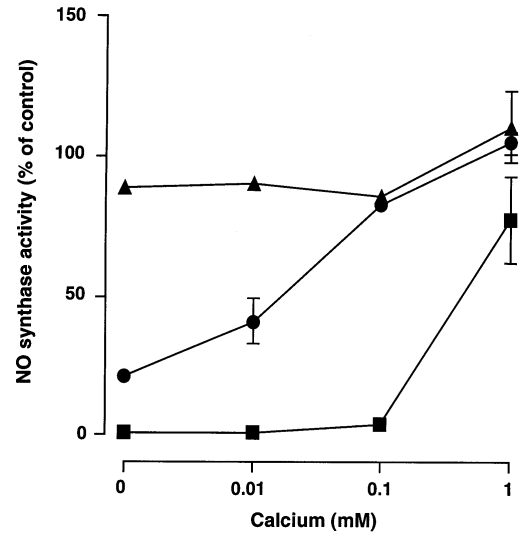

Figure 2 Requirement of free $\mathrm{Ca}^{2+}$ for NOS activity

The control reactions were performed with $1 \mathrm{mM} \mathrm{CaCl}_{2}$ and $100 \mathrm{nM}$ calmodulin but without EGTA. The control activities of guinea-pig iNOS, human iNOS and rat nNOS were $2.76 \pm 0.04$, $0.65 \pm 0.03$ and $1.40 \pm 0.10 \mathrm{pmol} / \mathrm{min}$ per $\mathrm{mg}$ of protein respectively (means \pm S.E.M.). Guinea-pig lung iNOS activity (O) was inhibited by $79 \%$ by $1 \mathrm{mM} \mathrm{EGTA} \mathrm{(zero} \mathrm{free} \mathrm{Ca}^{2+}$ ). Under the same conditions, human chondrocyte iNOS ( $\mathbf{A}$ ) was not significantly decreased, whereas rat nNOS activity ( $\boldsymbol{\square}$ ) was completely abolished. The guinea-pig iNOS activity was restored in a $\mathrm{Ca}^{2+}$-concentration-dependent manner. Each point is the mean \pm S.E.M. for four experiments.

\section{Expression of cDNA and characterization of recombinant enzyme}

To confirm the NOS activity of the cloned cDNA, the cDNA was expressed in COS cells. The COS cells transfected with the cloned cDNA produced large amounts of nitrite in the culture medium under resting conditions (results not shown). The cell lysates transfected with this cDNA also showed significant conversion activities of arginine to citrulline, whereas the lysates transfected with the vector alone had negligible activities (results not shown). It was confirmed that the conversion of $\left[{ }^{3} \mathrm{H}\right]$ arginine to $\left[{ }^{3} \mathrm{H}\right]$ citrulline was linear for at least $30 \mathrm{~min}$. Therefore, in all the assays of NOS activity, the reactions were stopped after $15 \mathrm{~min}$ of incubation.

Next we examined the requirement of free $\mathrm{Ca}^{2+}$ for NOS activity (Figure 2). The activity of the guinea-pig NOS was inhibited significantly (by $79 \%$ ) by the replacement of $\mathrm{CaCl}_{2}$ in the reaction buffer with $1 \mathrm{mM}$ EGTA. In contrast, the human chondrocyte iNOS activity was not significantly affected by EGTA but the activity of rat nNOS extracted from brain tissue was completely abolished by $\mathrm{Ca}^{2+}$ chelation. The enzyme activity of the guinea-pig NOS was recovered in a concentrationdependent manner by increasing the free $\mathrm{Ca}^{2+}$ level. To examine whether this partial dependence on $\mathrm{Ca}^{2+}$ was due to $\mathrm{Ca}^{2+}$ dependent calmodulin binding, trifluoperazine, a calmodulin antagonist, was added to the reaction buffer at a final concentration of $10-1000 \mu \mathrm{M}$. Trifluoperazine inhibited the activity of the guinea-pig NOS in a concentration-dependent manner in the presence of $100 \mathrm{nM}$ calmodulin (Figure 3). Trifluoperazine (1 $\mathrm{mM})$ suppressed the guinea-pig NOS and the human chondrocyte iNOS by $95 \%$ and $69 \%$ respectively. In contrast, $100 \mu \mathrm{M}$ trifluoperazine was enough to abolish the activity of rat nNOS completely. These results suggest that the partial $\mathrm{Ca}^{2+}$-dependence of the guinea-pig NOS is caused by the $\mathrm{Ca}^{2+}$-dependent binding of calmodulin to the enzyme.

To confirm that the cloned guinea-pig NOS belongs to the inducible isoform of NOS, preferential inhibitors of either iNOS or nNOS were added to the assay buffer (Table 1). We used $1400 \mathrm{~W}$ as the selective iNOS inhibitor and L-thiocitrulline as the 


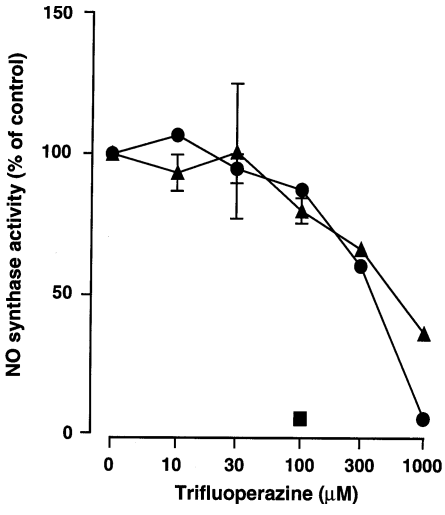

Figure 3 Requirement of calmodulin binding for NOS activity

The control reactions were performed with $1 \mathrm{mM} \mathrm{CaCl}$, and $100 \mathrm{nM}$ calmodulin. The control activities of guinea-pig iNOS, human iNOS and rat nNOS were $1.95 \pm 0.03,0.41 \pm 0.03$ and $3.26 \pm 0.20 \mathrm{pmol} / \mathrm{min}$ per $\mathrm{mg}$ of protein respectively (means \pm S.E.M.). Trifluoperazine inhibited both guinea-pig iNOS (-) and human chondrocyte iNOS $(\boldsymbol{\Delta})$ in a concentration-dependent manner. Trifluoperazine $(100 \mu \mathrm{M})$ was sufficient to abolish rat nNOS activity completely ( Each point is the mean \pm S.E.M. for four experiments.

\section{Table 1 Effect of selective inhibitors on NOS activity}

The control reactions were performed with all the cofactors and $1 \mathrm{mM} \mathrm{CaCl}$. The control activities of guinea-pig iNOS, human iNOS and rat nNOS were $2.12 \pm 0.05,0.37 \pm 0.03$ and $2.38 \pm 0.50 \mathrm{pmol} / \mathrm{min}$ per $\mathrm{mg}$ of protein respectively (means \pm S.E.M.). A concentration of $300 \mathrm{nM} 1400 \mathrm{~W}$ preferentially inhibited both guinea-pig and human iNOS compared with rat nNOS. In contrast, $100 \mathrm{nM}$ L-thiocitrulline decreased the activity of rat nNOS significantly more than those of guinea-pig and human iNOS. Each value is the mean \pm S.E.M. for four experiments. ${ }^{*} P<0.05$.

\begin{tabular}{|c|c|c|c|c|}
\hline \multirow[b]{2}{*}{ Inhibitor } & \multirow[b]{2}{*}{ Concentration (nM) } & \multicolumn{3}{|c|}{ Activity (\% of control) } \\
\hline & & Guinea-pig iNOS & Human iNOS & Rat nNOS \\
\hline \multirow[t]{3}{*}{$1400 \mathrm{~W}$} & 30 & $94.2 \pm 3.3$ & $90.2 \pm 4.3$ & $93.9 \pm 4.6$ \\
\hline & 100 & $84.3 \pm 1.6$ & $86.0 \pm 7.7$ & $93.5 \pm 5.0$ \\
\hline & 300 & $52.9 \pm 1.2^{*}$ & $53.6 \pm 4.3^{\star}$ & $72.5 \pm 4.2$ \\
\hline \multirow[t]{3}{*}{ L-Thiocitrulline } & 10 & $90.2 \pm 2.2$ & $112.5 \pm 6.8$ & $86.0 \pm 4.0$ \\
\hline & 100 & $78.3 \pm 3.6$ & $85.2 \pm 5.4$ & $59.3 \pm 1.3^{*}$ \\
\hline & 1000 & $28.1 \pm 4.9$ & $23.8 \pm 7.2$ & $21.3 \pm 3.4$ \\
\hline
\end{tabular}

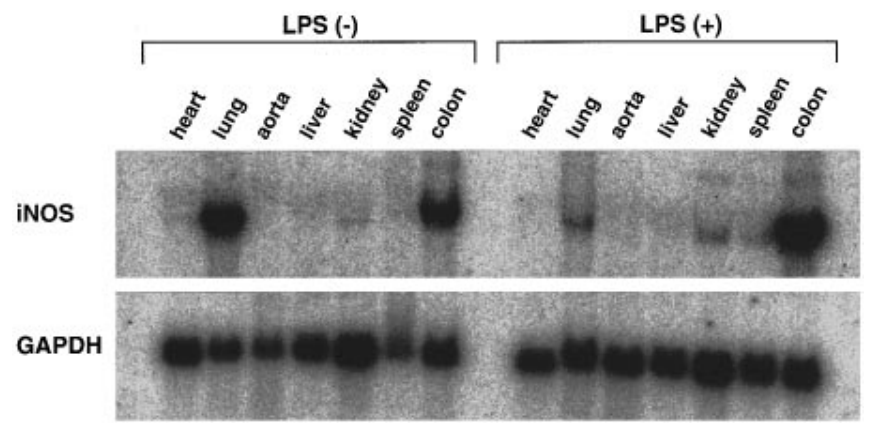

Figure 4 Northern blot analysis of guinea-pig iNOS mRNA

Constitutive iNOS expression was detected in the lung and the colon in normal guinea pigs. Stimulation with LPS inhibited iNOS mRNA expression in the lung, whereas in the kidney, the spleen and the colon the same stimulation induced its expression. RNA loading was assessed by probing with glyceraldehyde-3-phosphate dehydrogenase (GAPDH). selective nNOS inhibitor. 1400W significantly inhibited guineapig NOS compared with rat nNOS, whereas L-thiocitrulline decreased the activity of rat nNOS significantly more than that of guinea-pig NOS.

\section{Northern blot analysis}

A Northern blot analysis of total RNA from various guinea-pig tissues was performed with the cloned cDNA as the probe (Figure 4). A single $4.2 \mathrm{~kb}$ band of guinea-pig NOS was detected in the lung and the colon under physiological conditions. No signals were identified in the other tissues examined. Surprisingly, stimulation with LPS decreased the expression of NOS in the lung but induced its expression in the kidney, the spleen and the colon.

\section{DISCUSSION}

We constructed the full-length NOS cDNA by ligating two overlapping PCR products. Therefore it is possible that the cDNA is a chimaera of iNOS and other NOS isoforms. However, the nucleotide sequence of the $739 \mathrm{bp} \mathrm{PCR}$ fragment, which overlaps both the $\mathrm{N}$-terminal side and the $\mathrm{C}$-terminal side of the PCR products, was completely identical to the full-length cDNA. This result verifies that the cloned cDNA is not a chimaera.

The $\mathrm{A}(\mathrm{T})_{n} \mathrm{~A}$ motifs present in the $3^{\prime}$ untranslated region of the cDNA are specific for iNOS in three distinct NOS isoforms $[5,21]$. The deduced amino acid sequence is approx. $80 \%$ identical with previously described iNOSs from other species but less than $40 \%$ identical with nNOSs and eNOSs. It lacks an autoinhibitory regulatory insert in the FMN-binding domains, which is specific for eNOSs and nNOSs and prevents calmodulin binding and enzymic activation [19]. In the N-terminal portion it has no potential myristoylation site, which has been identified in eNOS [22]. In the transient expression study, the COS cells transfected with this cDNA showed significant levels of NOS activity under resting conditions. It has been shown that cells transfected with nNOS and eNOS require stimulation for NOS activation, which causes an influx of $\mathrm{Ca}^{2+}$ [23]. Furthermore, this NOS activity was selectively inhibited by $1400 \mathrm{~W}$ but not by L-thiocitrulline. Finally, stimulation with LPS in vivo induced mRNA expression in the kidney, the spleen and the colon. All these findings suggest that the cloned cDNA is the homologue of guinea-pig iNOS.

In the transfection study, the activity of the guinea-pig lung iNOS was obviously $\mathrm{Ca}^{2+}$-dependent. The enzyme was active at least at intracellular $\mathrm{Ca}^{2+}$ levels above physiological. However, NOS activity of the COS cell lysates transfected with the guineapig iNOS was significantly decreased by the removal of free $\mathrm{Ca}^{2+}$. In the same experiment, the human chondrocyte iNOS was slightly but not significantly inhibited by $\mathrm{Ca}^{2+}$ chelation. In this study we extracted iNOS in buffer containing $1 \mathrm{mM}$ EDTA. Stuehr and Griffith [24] demonstrated that the iNOS activity of macrophage lysate was partly inhibited when extracted in buffer containing chelating agents for divalent metal ions. Human hepatocyte iNOS and rat liver iNOS, when both purified with EDTA, are also partly $\mathrm{Ca}^{2+} /$ calmodulin-dependent $[5,10]$. It is therefore possible that extraction with $\mathrm{Ca}^{2+}$ chelators dissociates calmodulin from iNOS, which makes iNOS $\mathrm{Ca}^{2+}$-dependent. Recently Salerno et al. [19] have demonstrated that constitutively expressed isoforms of NOS have an autoinhibitory control element within the FMN-binding domain that impedes $\mathrm{Ca}^{2+}$ dependent calmodulin binding. They propose that the absence of this autoinhibitory polypeptide from iNOS contributes to an enhanced calmodulin affinity at low $\mathrm{Ca}^{2+}$ levels. The guinea-pig lung iNOS lacks this polypeptide insert. By their definition the guinea-pig iNOS should be $\mathrm{Ca}^{2+}$-independent. However, Ruan et 
al. [23] have demonstrated that the $\mathrm{N}$-terminal region and also the $\mathrm{C}$-terminal region adjacent to the canonical calmodulin binding domain are required for $\mathrm{Ca}^{2+}$-independent calmodulin binding to iNOS. In addition, Venema et al. [25] have demonstrated that iNOS/eNOS chimaeras that reciprocally replace the iNOS and eNOS calmodulin-binding domain show significant differences in $\mathrm{Ca}^{2+}$ and calmodulin dependence from the intact enzymes. Therefore it is possible that in addition to the autoinhibitory polypeptide insert, the canonical calmodulin-binding domain and other unidentified sites have an important role in the $\mathrm{Ca}^{2+}$ dependence.

Northern blot analysis shows that the guinea-pig iNOS is expressed constitutively in the lung and the colon. We obtained the same results by using the $3^{\prime}$ untranslated region specific for iNOS and also human chondrocyte iNOS as the probe (results not shown). Therefore it is unlikely that the $4.2 \mathrm{~kb}$ signals in Northern blot analysis are a cross-hybridization with other NOS isoforms. Furthermore, it is unlikely that constitutive iNOS expression is due to repeated exposure to environmental stimuli that induce cytokines because we used specific pathogen-free guinea pigs. Several articles have demonstrated that iNOS is expressed constitutively in some tissues and cell lines [6,7], although its physiological roles have not been clarified. In the present study, treatment with LPS in vivo induced the expression of iNOS in the kidney, the spleen and the colon. In contrast, iNOS expression in the lung was decreased markedly by stimulation with LPS. Up-regulation of NOS activity by stimulation with LPS and/or proinflammatory cytokines is one of the definitions of the inducible isoform of NOS. Therefore it is likely that the down-regulation of the expression of iNOS mRNA in the lung is due to a secondary effect of stimulation with LPS. It is possible that treatment with LPS increases the release of transforming growth factor $\beta 1$ from alveolar macrophages [26], which suppresses the expression of iNOS by decreasing the transcription and increasing the degradation of the mRNA $[27,28]$. Investigations of this distinctive iNOS found in the guinea pig will provide opportunities to clarify the diverse functions of iNOS.

\section{REFERENCES}

1 Knowles, R. G. and Moncada, S. (1994) Biochem. J. 298, 249-258

2 Nathan, C. and Xie, Q.-W. (1994) J. Biol. Chem. 269, 13725-13728
3 Cho, H. J., Xie, Q.-W., Calaycay, J., Mumford, R. A., Swiderek, K. M., Lee, T. D. and Nathan, C. (1992) J. Exp. Med. 176, 599-604

4 Palmer, R. M. J., Andrews, T., Foxwell, N. A. and Moncada, S. (1992) Biochem. Biophys. Res. Commun. 188, 209-215

5 Geller, D. A., Lowenstein, C. J., Shapiro, R. A., Nussler, A. K., DiSilvio, M., Wang, S. C., Nakayama, D. K., Simmons, R. L., Snyder, S. H. and Billiar, T. R. (1993) Proc. Natl. Acad. Sci. U.S.A. 90, 3491-3495

6 Guo, F. H., De Raeve, H. R., Rice, T. W., Stuehr, D. J., Thunnissen, F. B. J. M. and Erzurum, S. C. (1995) Proc. Natl. Acad. Sci. U.S.A. 92, 7809-7813

7 Mannick, J. B., Asano, K., Izumi, K., Kieff, E. and Stamler, J. S. (1994) Cell 79, 1137-1146

8 Salter, M., Knowles, R. G. and Moncada, S. (1991) FEBS Lett. 291, 145-149

9 Lyons, C. R., Orloff, G. J. and Cunningham, J. M. (1992) J. Biol. Chem. 267, 6370-6374

10 Adachi, H., lida, S., Oguchi, S., Ohshima, H., Suzuki, H., Nagasaki, K., Kawasaki, H., Sugimura, T. and Esumi, H. (1993) Eur. J. Biochem. 217, 37-43

11 Charles, I. G., Palmer, R. M. J., Hickery, M. S., Bayliss, M. T., Chubb, A. P., Hall, V. S., Moss, D. W. and Moncada, S. (1993) Proc. Natl. Acad. Sci. U.S.A. 90 $11419-11423$

12 Bradford, M. M. (1976) Anal. Biochem. 72, 248-254

13 Garvey, E. P., Oplinger, J. A., Furfine, E. S., Kiff, R. J., Laszlo, F., Whittle, B. J. R. and Knowles, R. G. (1997) J. Biol. Chem. 272, 4959-4963

14 Frey, C., Narayanan, K., McMillan, K., Spack, L., Gross, S. S., Masters, B. S. and Griffith, O. W. (1994) J. Biol. Chem. 269, 26083-26091

15 Kozak, M. (1991) J. Cell Biol. 115, 887-903

16 Shaw, G. and Kamen, R. (1986) Cell 46, 659-667

17 Hall, A. V., Antoniou, H., Wang, Y., Cheung, A. H., Arbus, A. M., Olson, S. L., Lu, W. C., Kau, C. L. and Marsden, P. A. (1994) J. Biol. Chem. 269, 33082-33090

18 Janssens, S. P., Shimouchi, A., Quertermous, T., Bloch, D. B. and Bloch, K. D. (1992) J. Biol. Chem. 267, 14519-14522

19 Salerno, J. C., Harris, D. E., Irizarry, K., Patel, B., Morales, A. J., Smith, S. M. E., Martasek, P., Roman, L. J., Masters, B. S. S., Jones, C. L. et al. (1997) J. Biol. Chem. 272, 29769-29777

20 Kemp, B. E. and Pearson, R. B. (1990) Trends Biochem. Sci. 15, 342-346

21 Geng, Y., Almqvist, M. and Hansson, G. K. (1994) Biochim. Biophys. Acta 1218 421-424

22 Sessa, W. C., Harrison, J. K., Barber, C. M., Zeng, D., Durieux, M. E., D’Angelo, D. D., Lynch, K. R. and Peach, M. J. (1992) J. Biol. Chem. 267, 15274-15276

23 Ruan, J., Xie, Q.-W., Hutchinson, N., Cho, H., Wolfe, G. C. and Nathan, C. (1996) J. Biol. Chem. 271, 22679-22686

24 Stuehr, D. J. and Griffith, O. W. (1992) Adv. Enzymol. 65, 287-346

25 Venema, R. C., Sayegh, H. S., Kent, J. D. and Harrison, D. G. (1996) J. Biol. Chem. 271, 6435-6440

26 Vignola, A. M., Chanez, P., Chiappara, G., Merendino, A., Zinnanti, E., Bousquet, J., Bellia, V. and Bonsignore, G. (1996) Clin. Exp. Immunol. 106, 114-119

27 Vodovotz, Y., Bogdan, C., Paik, J., Xie, Q.-W. and Nathan, C. (1993) J. Exp. Med. 178, 605-613

28 Perrella, M. A., Yoshizumi, M., Fen, Z., Tsai, J.-C., Hsieh, C.-M., Kourembanas, S. and Lee, M.-E. (1994) J. Biol. Chem. 269, 14595-14600

Received 21 November 1997/16 April 1998; accepted 11 May 1998 